\title{
Horizontal and Vertical Structures of the Northward-Propagating Intraseasonal Oscillation in the South Asian Monsoon Region Simulated by an Intermediate Model*
}

\author{
HaE-Kyung Lee Drbohlav and Bin Wang ${ }^{+}$ \\ Department of Meteorology, School of Ocean and Earth Science and Technology, University of Hawaii at Manoa, Honolulu, Hawaii
}

(Manuscript received 30 March 2006, in final form 4 December 2006)

\begin{abstract}
The structures and mechanism of the northward-propagating boreal summer intraseasonal oscillation (BSISO) in the southern Asian monsoon region are simulated and investigated in a three-dimensional intermediate model (3D model). The horizontal structure of the intraseasonal variability in the 3D model depicts the Kelvin-Rossby wave-type disturbance, which may or may not produce the northward-propagating disturbance in the Indian Ocean, depending on the seasonal-mean background winds.

Two experiments are conducted in order to identify what characteristic of seasonal-mean background can induce the northwestward-tilted band in the Kelvin-Rossby wave, whose overall eastward movement gives the impression of the northward propagation at a given longitude. When the prescribed boreal summer mean winds are excluded in the first experiment, the phase difference between the barotropic divergence tendency and convection disappears. Consequently, the Rossby wave-type convection forms a zonally elongated band. As a result, the northward propagation of convection at a given longitude disappears. When the easterly vertical shear is introduced in the second experiment, the horizontal and the vertical structures of BSISO become similar to that of the northward-propagating one. The reoccurrence of the northwestward-directed convective band and the phase difference between the barotropic divergence tendency and the convection suggest that the summer mean zonal winds in the boreal Indian summer monsoon region are a critical condition that causes the horizontal and vertical structures of northward-propagating BSISO in the southern Asian monsoon region.
\end{abstract}

\section{Introduction}

One of the unique characteristics of the boreal summer intraseasonal oscillation (BSISO) is the northward propagation of convection over the Indian and western Pacific Ocean from May to October. Over the Indian Ocean, convection develops near the equator and moves northward with a speed of $0.75^{\circ}$ latitude per day (Krishnamurti and Subrahmanyam 1982). Due to its possible effect on the active/break phase of the Indian summer monsoon, the mechanism of this northward-

\footnotetext{
* International Pacific Research Institute Publication Number 451 and School of Ocean and Earth Science and Technology Publication Number 7102.

+ Current affiliation: Department of Meteorology and International Pacific Research Center, University of Hawaii at Manoa, Honolulu, Hawaii, and College of Marine Environment, Ocean University of China, Qingdao, China.
}

Corresponding author address: Hae-Kyung Lee Drbohlav, Center for Ocean-Land-Atmosphere Studies, 4041 Powder Mill Road, Suite 302, Calverton, MD 20705.

E-mail: hael@cola.iges.org propagating convection has been studied extensively. For example, Webster (1983) introduced the role of land surface heat fluxes on the northward propagation of convection, while Goswami and Shukla (1984) and Anderson and Stevens (1987) emphasized the role of moist static stability, controlled by the interaction between convection and radiative relaxation. The common conclusion of the above studies is that thermodynamic interaction in the atmosphere is the main cause of the northward propagation of BSISO.

In other studies, zonally propagating atmospheric waves are suggested to cause the northward propagation of convection. Yasunari (1979) and Lau and Chan (1986) indicated that the northward propagation of convection is linked to the eastward-propagating convection along the equator. Based on a modeling study, Wang and Xie (1997) proposed that the northward propagation of convection is formed by the Rossby wave component of the Kelvin-Rossby wave packet that propagates eastward along the equator. Later, Lawrence and Webster (2002) analyzed the outgoing longwave radiation (OLR) during June through September and argued that the impression of northward movement of convection at a given longitude is a result

DOI: $10.1175 / J C L I 4244.1$ 
of eastward movement of the northwest-southeastoriented band of convection. The conclusion of their study is that northward propagation of convection is not the result of an independent and unique summer mode but rather is a modified version of the winter intraseasonal oscillation.

Hsu et al. (2004) reported characteristics of northward-propagating BSISO associated with the eastward propagation along the equator. They attributed the northward propagation to the deep convergence extending from the surface to the middle troposphere. Since near-surface convergence appears only after the systems approach the landmass in the north, they suggested the lifting effect of the sloping terrain and the stronger surface friction over the land in South Asia contribute to the near-surface convergence north of the deep convection. They also found that surface sensible heating contributes to the northward propagation, especially in the Arabian Sea. The air-sea interaction on intraseasonal time scales (Kemball-Cook and Wang 2001; Fu et al. 2003) is also suggested as the mechanism of the northward propagation.

When a couple of mechanisms are suggested for the northward propagation, one way to investigate which process is the most essential is to get rid of the suggested specific mechanism from the model and to see if the northward-propagating intraseasonal oscillation can still be simulated. For example, if the northwardpropagating intraseasonal oscillation is still simulated in the absence of the air-sea interaction in the model, it implies that the air-sea interaction may not be the critical factor in producing the northward propagation.

Similarly, the zonally averaged model (Drbohlav 2002; Drbohlav and Wang 2005; Wang 2005) is used to specifically exclude the eastward-propagating KelvinRossby wave packet to see how critical this wave packet is in inducing the northward propagation. It turned out that even without the Kelvin-Rossby wave packet, the northward propagation can still be simulated in the model. This implied that the most fundamental mechanism of the northward propagation may not be imbedded in the eastward-moving Rossby-Kelvin wave packet but in the other mechanism of a two-dimensional model (2D model).

From this logic, they analyzed the mechanism of the northward propagation in their simple model. Since their model excluded the eastward-moving KelvinRossby wave packet, their mechanism is introduced as a "wave-independent mechanism." They conclude that the interaction between convection and the easterly vertical shear of basic zonal flow over the Indian Ocean region can induce the northward-propagating component of BSISO even in the absence of the zonally propagating wave packet. This conclusion is consistent with Jiang et al. (2004), who used a simple theoretical model to show the importance of the easterly vertical shear of boreal summer flow. However, the wave-independent mechanism of the northward propagation is deducted from the simple 2D model; thus, we do not know how this simple mechanism will work in a more complicated environment.

In this study, we used the three-dimensional model (3D model) to examine if the northward-propagating mechanism, suggested in the 2D model, is still effective in causing the northwestward-tilted band in the KelvinRossby wave packet. Since the easterly vertical shear in the mean wind flow is the most essential component in the mechanism of northward-propagating BSISO, two experiments with the different mean flows are conducted. By comparing the horizontal and vertical structures of northward-propagating BSISO among experiments, we attempt to examine whether the easterly vertical shear over the Indian Ocean during boreal summer can effectively modify the horizontal structure of the Kelvin-Rossby wave packet to produce the northwestward tilt in the convective disturbance.

\section{The model and basic states}

\section{a. The model}

The 3D intermediate model used in this study is identical to that developed by Wang and Xie (1997), with

TABLE 1. Model parameters.

\begin{tabular}{llc}
\hline \hline & \multicolumn{1}{c}{ Abbreviations and definitions } & Control run and expts 1 and 2 \\
\hline$P_{e}$ & Pressure at the top of the boundary layer & $900 \mathrm{hPa}$ \\
$p_{t}$ & Pressure at the top of the free atmosphere & $100 \mathrm{hPa}$ \\
$\varepsilon$ & Rayleigh friction coefficient & $0.5 \times 10^{-6} \mathrm{~s}^{-1}$ \\
$\mu$ & Newton cooling coefficient & $0.5 \times 10^{-6} \mathrm{~s}^{-1}$ \\
$E_{x}$ & Dissipation coefficient in the boundary layer & $1 \times 10^{-4} \mathrm{~s}^{-1}$ \\
$K$ & Horizontal diffusion coefficient & $5 \times 10^{5} \mathrm{~m}^{2} \mathrm{~s}^{-1}$ \\
$b$ & Precipitation efficiency coefficient & 0.72 \\
$S_{m}$ & Mean statistic stability parameter at the middle level & $3 \times 10^{-6} \mathrm{~m}^{2} \mathrm{~s}^{-2} \mathrm{~Pa}^{-2}$ \\
$m$ & Density scale height/water vapor density scale height & 3.4 \\
\hline
\end{tabular}


some changes in parameters (Table 1). The model consists of a two-level free atmosphere and one well-mixed boundary layer (Fig. 1). The subscripts 1, 2, and $m$ are used to indicate the upper $(300 \mathrm{hPa})$, lower $(700 \mathrm{hPa})$, and middle $(500 \mathrm{hPa})$ levels of the atmosphere, respectively, while the subscript $B$ represents the vertically averaged perturbation in the boundary layer, and the subscript $e$ represents the perturbation at the top of the boundary layer (Fig. 1). Momentum and continuity equations are applied at the upper and lower level of the free atmosphere, and the thermodynamic and hydrostatic equations are applied at the middle level $(500 \mathrm{hPa})$. Using these subscripts, the $3 \mathrm{D}$ perturbation primitive equations in a $P$ coordinate and equator $\beta$ plane are written as

$$
\begin{gathered}
\frac{\partial u_{1}^{\prime}}{\partial t}=-\bar{u}_{1} \frac{\partial u_{1}^{\prime}}{\partial x}-u_{1}^{\prime} \frac{\partial \bar{u}_{1}}{\partial x}-\bar{v}_{1} \frac{\partial u_{1}^{\prime}}{\partial y}-v_{1}^{\prime} \frac{\partial \bar{u}_{1}}{\partial y}-\bar{\omega}_{m} \frac{u_{2}^{\prime}-u_{1}^{\prime}}{\Delta p}-\omega_{m}^{\prime} \frac{\bar{u}_{2}-\bar{u}_{1}}{\Delta p}+\beta y v_{1}^{\prime}-\frac{\partial \phi_{1}^{\prime}}{\partial x}-\varepsilon u_{1}^{\prime}+K \nabla^{2} u_{1}^{\prime}, \\
\frac{\partial v_{1}^{\prime}}{\partial t}=-\bar{u}_{1} \frac{\partial v_{1}^{\prime}}{\partial x}-u_{1}^{\prime} \frac{\partial \bar{v}_{1}}{\partial x}-\bar{v}_{1} \frac{\partial v^{\prime}}{\partial y}-v_{2}^{\prime} \frac{\partial \bar{\nu}_{1}}{\partial y}-\bar{\omega}_{m} \frac{v_{2}^{\prime}-v_{1}^{\prime}}{\Delta p}-\omega_{m}^{\prime} \frac{\bar{v}_{2}-\bar{v}_{1}}{\Delta p}-\beta y u_{1}^{\prime}-\frac{\partial \phi_{1}^{\prime}}{\partial y}-\varepsilon v_{1}^{\prime}+K \nabla^{2} v_{1}^{\prime}, \\
\frac{\partial u_{1}^{\prime}}{\partial x}+\frac{\partial v_{1}^{\prime}}{\partial y}+\frac{\omega_{m}^{\prime}-0}{\Delta p}=0, \\
\frac{\partial u_{2}^{\prime}}{\partial t}=-\bar{u}_{2} \frac{\partial u_{2}^{\prime}}{\partial x}-u_{2}^{\prime} \frac{\partial \bar{u}_{2}}{\partial x}-\bar{v}_{2} \frac{\partial u_{2}^{\prime}}{\partial y}-v_{2}^{\prime} \frac{\partial \bar{u}_{2}}{\partial y}-\bar{\omega}_{m} \frac{u_{2}^{\prime}-u_{1}^{\prime}}{\Delta p}-\omega_{m}^{\prime} \frac{\bar{u}_{2}-\bar{u}_{1}}{\Delta p}+\beta y v_{2}^{\prime}-\frac{\partial \phi_{2}^{\prime}}{\partial x}-\varepsilon u_{2}^{\prime}+K \nabla^{2} u_{2}^{\prime}, \\
\frac{\partial v_{2}^{\prime}}{\partial t}=-\bar{u}_{2} \frac{\partial v_{2}^{\prime}}{\partial x}-u_{2}^{\prime} \frac{\partial \bar{v}_{2}}{\partial x}-\bar{v}_{2} \frac{\partial v_{2}^{\prime}}{\partial y}-v_{2}^{\prime} \frac{\partial \bar{v}_{2}}{\partial y}-\bar{\omega}_{m} \frac{v_{2}^{\prime}-v_{1}^{\prime}}{\Delta p}-\omega_{m}^{\prime} \frac{\bar{v}_{2}-\bar{v}_{1}}{\Delta p}-\beta y u_{2}^{\prime}-\frac{\partial \phi_{2}^{\prime}}{\partial y}-\varepsilon v_{2}^{\prime}+K \nabla^{2} v_{2}^{\prime}, \\
\frac{\partial u_{m}^{\prime}}{\partial x}+\frac{\partial v_{2}^{\prime}}{\partial y}+\frac{\omega_{e}^{\prime}-\omega_{m}^{\prime}}{\Delta p}=0, \\
\left.\frac{\phi_{2}^{\prime}-\bar{u}_{1}+\bar{u}_{2}}{2}\right) \frac{\partial T_{m}^{\prime}}{\partial x}-\left(\frac{u_{1}^{\prime}+u_{2}^{\prime}}{2}\right) \frac{\partial \bar{T}_{m}}{\partial x}-\left(\frac{\bar{v}_{1}+\bar{v}_{2}}{2}\right) \frac{\partial T_{m}^{\prime}}{\partial y}-\left(\frac{v_{1}^{\prime}+v_{2}^{\prime}}{2}\right) \frac{\partial \bar{T}_{m}}{\partial y}+\frac{p_{m}}{R} \bar{S} \omega_{m}^{\prime} \frac{Q_{m}^{\prime}}{C_{p}}-\mu T_{m}^{\prime}+K \nabla^{2} T^{\prime}
\end{gathered}
$$

where an overbar (prime) represents a basic-state (perturbation) quantity; $u, v, \omega, \phi, T$, and $Q_{m}$ denote zonal and meridional winds, vertical pressure velocity, geopotential, temperature, and condensational heating; $\varepsilon$, $\mu$, and $R$ are the Rayleigh friction coefficient, Newtonian cooling coefficient, and specific gas constant; $K$ is the turbulent horizontal momentum or thermal diffusion coefficient; $S$ is the dry static stability parameter at the middle of the atmosphere; and $\Delta p$ is the half-depth of the free troposphere.

The governing equations in a steady, well-mixed boundary layer can be described as

$$
\begin{aligned}
\beta y v_{B}^{\prime}-\frac{\partial \phi_{e}^{\prime}}{\partial x}-E_{x} u_{B}^{\prime} & =0, \\
-\beta y u_{B}^{\prime}-\frac{\partial \phi_{e}^{\prime}}{\partial y}-E_{y} v_{B}^{\prime} & =0, \quad \text { and } \\
\omega_{e}^{\prime} & =\left(p_{s}-p_{e}\right)\left(\frac{\partial u_{B}^{\prime}}{\partial x}+\frac{\partial v_{B}^{\prime}}{\partial y}\right),
\end{aligned}
$$

where $p_{s}$ and $p_{e}$ are the pressure at the model surface and top of the boundary layer; $\phi_{e}^{\prime}$ denotes perturbation geopotential at $p_{e} ; u_{B}^{\prime}$ and $v_{B}^{\prime}$ are the perturbation zonal and meridional winds in the boundary layer; and $E_{x}$ and $E_{y}$ are Rayleigh friction coefficients in the zonal and meridional directions. From (2), the Ekman pumping velocity can be written as

$$
\omega_{e}^{\prime}=D_{1} \frac{\partial^{2} \phi_{e}^{\prime}}{\partial x^{2}}+D_{2} \frac{\partial \phi_{e}^{\prime}}{\partial x} D_{3} \frac{\partial^{2} \phi_{e}^{\prime}}{\partial y^{2}}+D_{4} \frac{\partial \phi_{e}^{\prime}}{\partial y},
$$

where the coefficients are

$$
\begin{aligned}
& D_{1}=-\frac{\left(P_{s}-P_{e}\right) E_{y}}{E_{x} E_{y}+\beta^{2} y^{2}}, \\
& D_{2}=\frac{\left(P_{s}-P_{e}\right) \beta}{E_{x} E_{y}+\beta^{2} y^{2}}-\frac{2\left(P_{s}-P_{e}\right) \beta^{3} y^{2}}{\left(E_{x} E_{y}+\beta^{2} y^{2}\right)^{2}}, \\
& D_{3}=-\frac{\left(P_{s}-P_{e}\right) E_{x}}{E_{x} E_{y}+\beta^{2} y^{2}}, \text { and } \\
& D_{4}=\frac{2\left(P_{s}-P_{e}\right) E_{x} \beta^{2} y}{\left(E_{x} E_{y}+\beta^{2} y^{2}\right)^{2}} .
\end{aligned}
$$




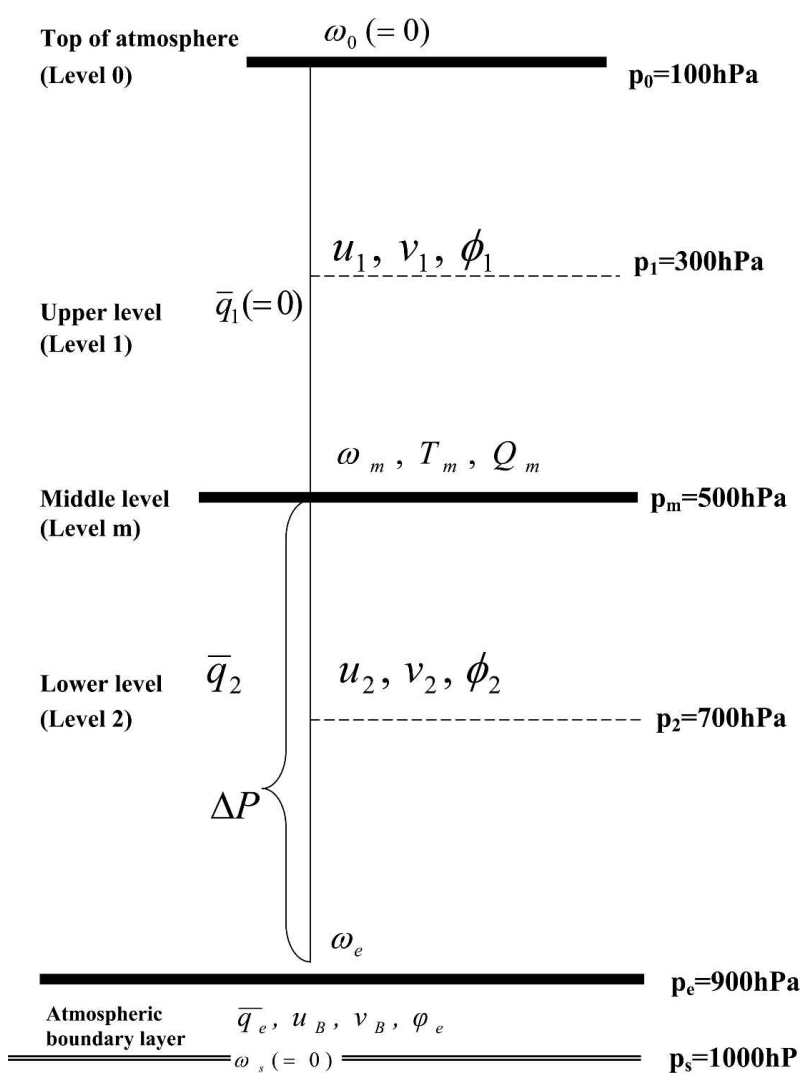

FIG. 1. Schematic diagram of the model.

Due to mass conservation in a fixed vertical column, the Ekman pumping velocity in the barotropic boundary layer is related to free tropospheric divergence as follows:

$$
\omega_{e}^{\prime}=-\Delta P \sum_{k=1}^{2}\left(\frac{\partial u_{k}^{\prime}}{\partial x}+\frac{\partial v_{k}^{\prime}}{\partial y}\right)
$$

Combining (3) and (4) leads to an elliptical equation for $\phi_{e}^{\prime}$ :

$$
\begin{aligned}
D_{1} \frac{\partial^{2} \phi_{e}^{\prime}}{\partial x^{2}}+ & D_{2} \frac{\partial \phi_{e}^{\prime}}{\partial x}+D_{3} \frac{\partial^{2} \phi_{e}^{\prime}}{\partial y^{2}}+D_{4} \frac{\partial \phi_{e}^{\prime}}{\partial y}= \\
& -\Delta P \sum_{k=1}^{2}\left(\frac{\partial u_{K}^{\prime}}{\partial x}+\frac{\partial v_{K}^{\prime}}{\partial y}\right) .
\end{aligned}
$$

Here, the assumption, $\phi_{e}^{\prime}=\phi_{2}^{\prime}$ is made in order to close the governing equations.

The precipitation rate $(\mathrm{Pr})$ and the condensational heating $\left(Q_{m}^{\prime}\right)$ at the middle atmosphere $P_{m}$ are expressed as

$$
\begin{aligned}
\operatorname{Pr} & =-\omega_{e}^{\prime}\left(\bar{q}_{e}-\bar{q}_{2}\right)-\omega_{m}^{\prime} \bar{q}_{2} \text { and } \\
Q_{m}^{\prime} & =\frac{\delta b L_{c}}{\Delta p}\left[-\omega_{m}^{\prime} \bar{q}_{2}-\omega_{e}^{\prime}\left(\bar{q}_{e}-\bar{q}_{2}\right)\right],
\end{aligned}
$$

where $\bar{q}_{e}$ and $\bar{q}_{2}$ are specific humidity of June-JulyAugust mean climatology; $Q_{m}^{\prime}$ represents irreversible condensational heating; $b$ measures the ratio of the amount of water vapor that condenses out to the total moisture convergence in the same air column; and $L_{c}$ is the latent heat.

The meridional domain of the model is confined to an equatorial $\beta$ plane between $40^{\circ} \mathrm{S}$ and $40^{\circ} \mathrm{N}$. At the meridional boundaries, the perturbation fluxes of mass, momentum, and heat normal to the boundaries vanish. In analyzing the mechanism of the northward propagation, the barotropic mode $\left(A^{+}\right)$and baroclinic mode $\left(A^{-}\right)$of an arbitrary variable $(A)$ are defined as

$$
A^{+}=\frac{A_{1}+A_{2}}{2} \text { and } A^{-}=\frac{A_{1}-A_{2}}{2} .
$$

\section{b. Design of experiments}

Two experiments are conducted using the different basic states from the control run. The prescribed basic state of the control run represents the mean climate state of boreal summer. The free-atmospheric moisture content (specific humidity, Fig. 2a), winds (Figs. 2b,c), and temperature (figure not shown) are calculated by averaging June-August values from the 40-yr European Centre for Medium-Range Weather Forecasts (ECMWF) Re-Analysis (ERA-40) data for the period 1979-92. In addition, the surface moisture availability is already considered in specific humidity (Fig. 2a), following the criteria by Fu and Wang (1999). The distinct features of a June-August mean state (summer mean state hereafter) are the maximum of specific humidity in the northern Indian Ocean from $10^{\circ}$ to $25^{\circ} \mathrm{N}$ (Fig. 2a) and the easterly vertical shear (easterly increases with height) over the Indian region $\left(60^{\circ}-120^{\circ} \mathrm{E}\right)$ from the equator to $20^{\circ} \mathrm{N}$ (Fig. 2d).

In the first experiment (experiment 1), the BSISO is simulated with no basic-state atmospheric circulation, while the thermodynamic basic-state variables, such as specific humidity content and temperature, are kept unchanged (8a). Since the exclusion of basic-state winds is the only difference between control run and experiment 1 , the BSISO in experiment 1 represents the oscillation caused by the atmospheric wave under the absence of the summer mean easterly shear. In the second experiment (experiment 2), zonally uniform summer mean zonal winds are included [(8b); Figs. 3a,b], while the summer mean of the meridional and vertical winds is still excluded. Zonally uniform summer mean zonal winds are obtained by averaging zonal flows over the longitudes from $60^{\circ}$ to $100^{\circ} \mathrm{E}$. Compared to experiment 1 , the effect of meridional and vertical variations of summer mean zonal winds over the Indian Ocean region are added in experiment 2 . That is, 
(a) Climatology J.J.A. mean specific humidity [unitless]

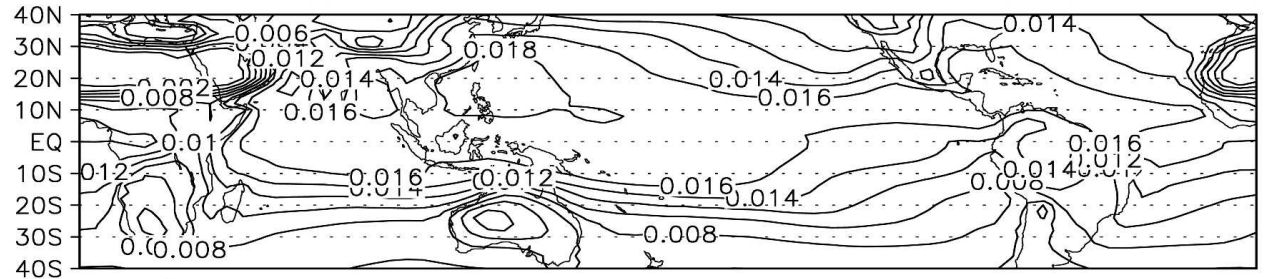

(b) Climatology J.J.A. mean $850 \mathrm{hPa}$ winds

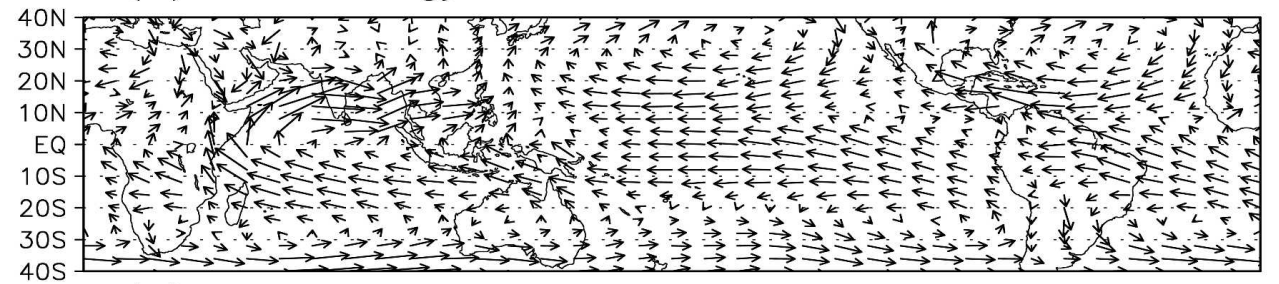

(c) Climatology J.J.A. mean $200 h P a$ winds

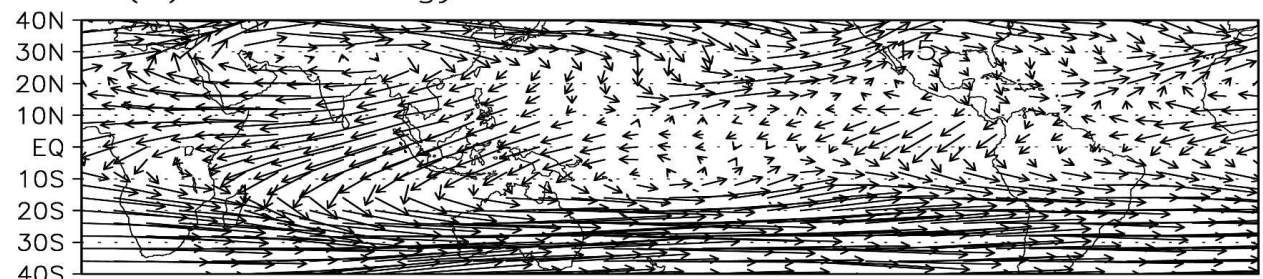

(d) J.J.A. mean vertical wind shear (200hPa-850hPa) $[\mathrm{m} / \mathrm{s}]$

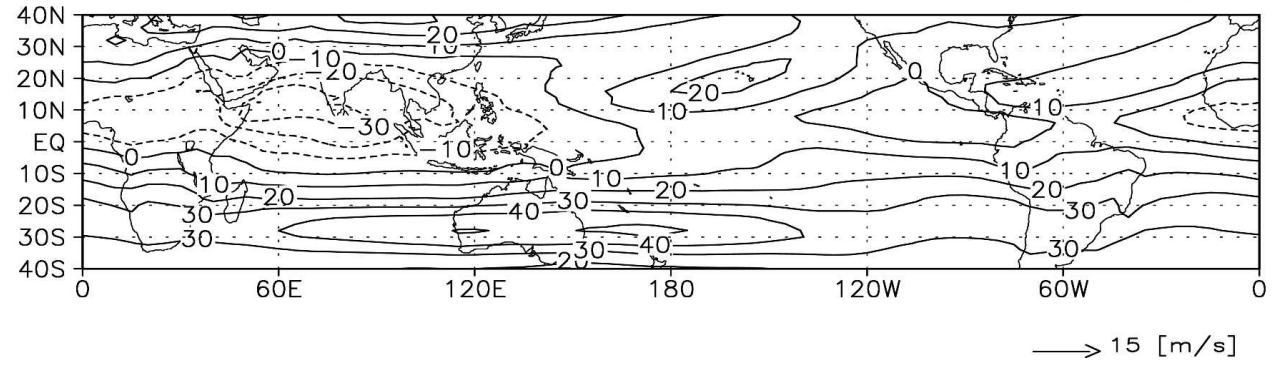

FIG. 2. The climatological (a) June-August mean specific humidity at $1000 \mathrm{hPa}$, (b) June-August mean winds at $850 \mathrm{hPa}$, (c) June-August mean winds at $200 \mathrm{hPa}$, and (d) the vertical shear of June-August mean zonal winds (200-850 hPa), estimated from ECMWF global analyses (ERA-40) for the period 1979-92.

$$
\begin{aligned}
& \bar{u}=\bar{v}=\bar{\omega}=0 \text { in experiment } 1 \text { and } \\
& \bar{v}=\bar{\omega}=0, \bar{u}(y, z) \text { in experiment } 2 .
\end{aligned}
$$

While the results of experiment 1 highlight the role of pure atmospheric waves on the BSISO, the intraseasonal oscillation simulated from experiment 2 represents a result of the added effect of vertical shear on the atmospheric waves. Specifically, the comparison between experiment 1 and experiment 2 will emphasize how important the summer mean zonal winds are in modifying the classical Kelvin-Rossby wave-type BSISO. In the following sections, responses of BSISO to these two experiments and control run are compared in terms of spatial structures, northward-propagating patterns, and the phase difference between the barotropic divergence and the convection.

\section{Results of the control run and experiments}

\section{a. Dissipation of BSISO}

Although the spatial evolution of BSISO is repeated in the numerical simulation, the intensity of BSISO decreases throughout the simulation. The time series of the spatial maximum of precipitation rate (Fig. 3c) is used to indicate the dissipating rate of BSISO. The spatial maximum of precipitation rate ( $\mathrm{Pr}_{\text {SMAX }}$ hereafter) at each time step can be defined by the maximum value of precipitation within a domain from $40^{\circ} \mathrm{S}$ to $40^{\circ} \mathrm{N}, 0^{\circ}$ to $360^{\circ} \mathrm{E}$. In general, the intensity of anomalies decreases after each life cycle, while the spatial and vertical structures of BSISO are preserved. These preserved structures of BSISO can be extracted by dividing variables (e.g., precipitation rate) with their spatial 

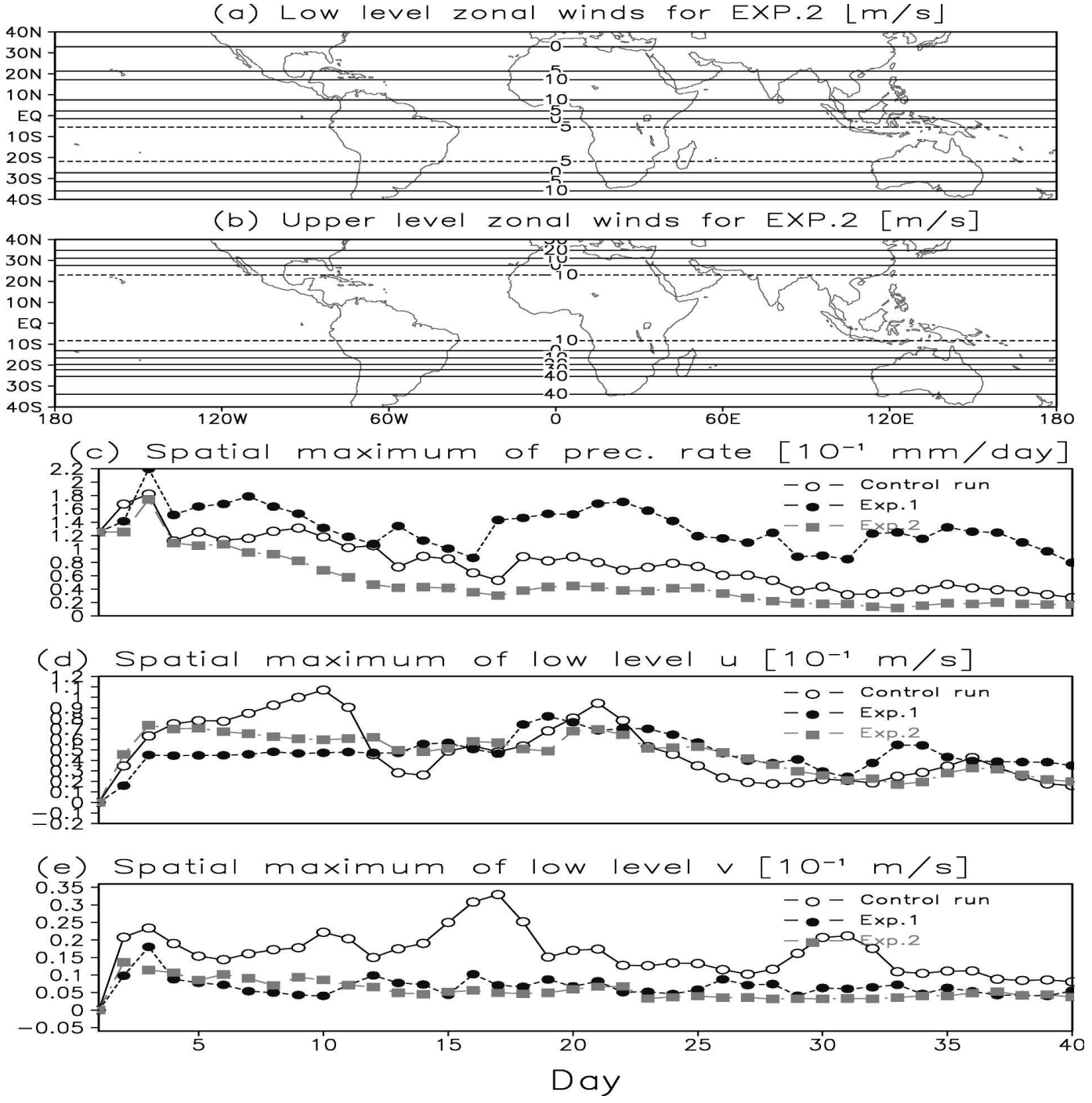

FIG. 3. Zonally uniform zonal winds at (a) 850 and (b) $200 \mathrm{hPa}$, used as mean-state winds in expt 2. Time series of spatial maximum in (c) precipitation rate, (d) low-level zonal winds, and (e) low-level meridional winds for the control run and expts 1 and 2. These spatial maxima are used as denominators in calculating the dimensionless precipitation and winds in Fig. 4.

maximum values (Pr.smax). Since each anomaly is divided by the spatial maximum value, the result ranges from 0 to 1 at each time step. This procedure allows us to concentrate on the spatial structure of BSISO.

\section{b. Spatial structure of BSISO in control run and experiments 1 and 2}

To concentrate on the spatial and vertical structures of BSISO, variables such as precipitation, zonal wind, and meridional wind anomalies are divided by their spatial maximum values (Figs. 3c-e) and presented as "dimensionless" form. In the control run, the precipitation cell located at the equator in day 1 (Fig. 4a) moves eastward and reaches $120^{\circ} \mathrm{E}$ on day 5 (Fig. 4c). Meanwhile, the off-equatorial convective cell is found between $60^{\circ}$ and $120^{\circ} \mathrm{E}$. During the formation of this diagonal-shaped band from day 5 to day 9, convection gives an impression of northward propagation, if observed at a fixed longitude (Fig. 5a). When summer mean flows are excluded in experiment 1, the off-equatorial convection develops both in the Northern and Southern Hemispheres when an eastward-moving Kelvin-type disturbance passes maritime continents near $120^{\circ} \mathrm{E}$ (Fig. $4 \mathrm{~h}$ ); however, this offequatorial convection is elongated in the zonal rather than the diagonal direction (Figs. $4 \mathrm{~h}-\mathrm{j}$ ). Thus, the northward-propagating impression is not shown in Fig. $5 b$, even when the precipitation of experiment 1 is zonally averaged to emphasize the latitudinal variation.

In experiment 2, where zonally uniform summer 


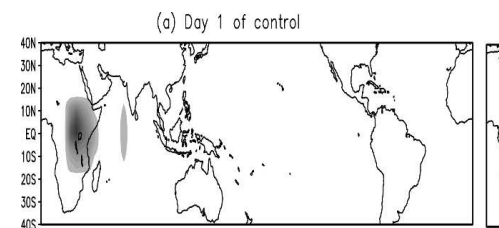

(b) Day 3 of control

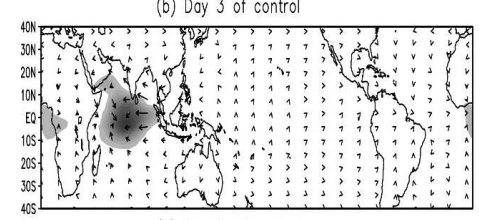

(c) Day 5 of control

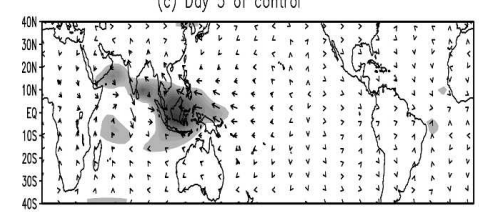

(d) Day 7 of control

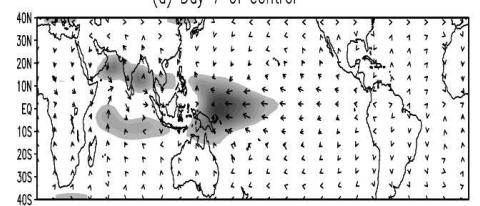

(e) Day 9 of control

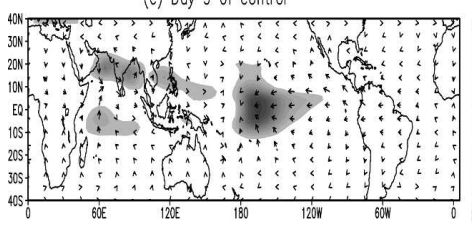

(f) Doy 1 of EXP.1

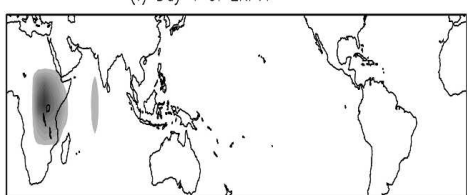

(g) Day 3 of EXP.1

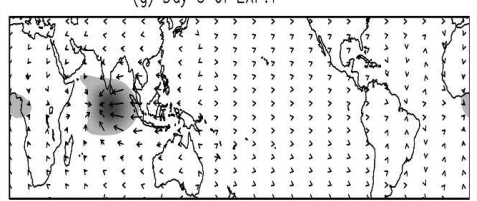

(h) Day 5 of EXP.1

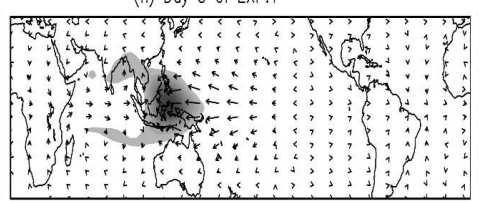

(i) Day 7 of EXP.1

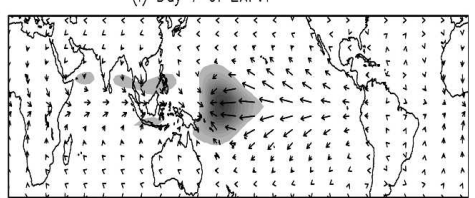

(j) Doy 9 of EXP.1

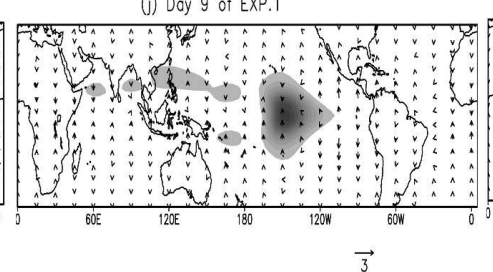

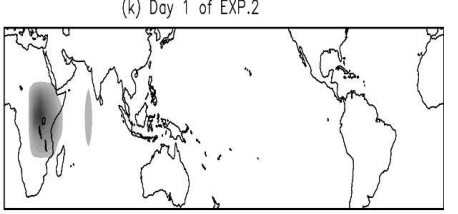

(I) Day 3 of EXP.2

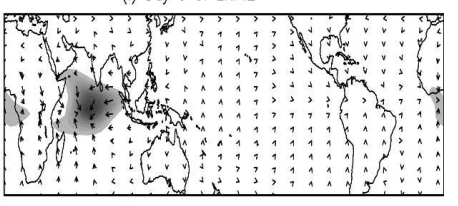

(m) Doy 5 of EXP.2

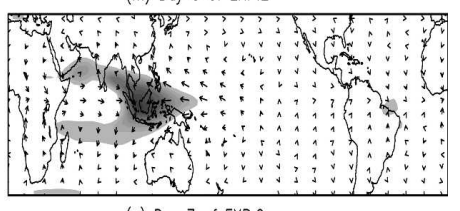

(n) Day 7 of EXP.2

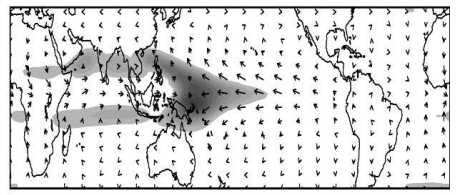

(o) Day 9 of EXP.2

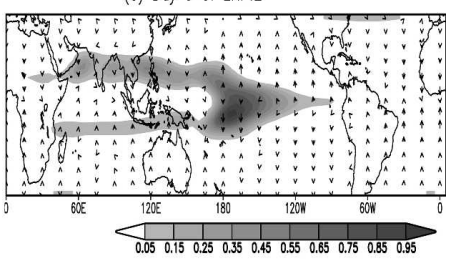

Dimensionless low level winds

FIG. 4. Sequential maps for the dimensionless lower-tropospheric winds and dimensionless precipitation rate in the control run on days (a) 1, (b) 3, (c) 5, (d) 7, and (e) 9; expt 1 on days (f) 1, (g) 3, (h) 5, (i) 7, and (j) 9; and expt 2 on days (k) 1 , (l) 3, (m) 5, (n) 7, and (o) 9 .

mean zonal flows (Figs. 3a,b) are added, convection is organized into the diagonal band and extended from the equator to the northern Indian Ocean on day 5 (Fig. $4 \mathrm{~m})$. In addition, the off-equatorial convection is still associated with the equatorial convection as seen on day 9 (Fig. 4o). Since the entire domain $\left(40^{\circ} \mathrm{S}-40^{\circ} \mathrm{N}\right.$, $0^{\circ}-360^{\circ}$ ) in experiment 2 is replaced by the zonally averaged summer mean zonal flows of the Indian Ocean region $\left(60^{\circ}-100^{\circ} \mathrm{E}\right)$, the effect of zonal winds is no longer confined within the Indian Ocean region. Consequently, the intensification of the off-equatorial disturbance is also found outside of the Indian Ocean region in experiment 2 (Fig. 4, right panels).

\section{c. Northward propagation of BSISO}

In Fig. 5, the dimensionless precipitation rates of the control run, experiment 1 , and experiment 2 are zonally averaged over $60^{\circ}$ and $100^{\circ} \mathrm{E}$. It is evident that the northward propagation of convection from $0^{\circ}$ to $25^{\circ} \mathrm{N}$ is most evident in the control run (Fig. 5a) and least pro- nounced in experiment 1 (Fig. 5b). The reappearance of the northward propagation in experiment 2 implies the importance of the easterly vertical shear in the seasonal-mean zonal winds. This result is consistent with the mechanism suggested by Drbohlav and Wang (2005). They argued that when the anomalous convection develops under the characteristics of easterly vertical shear in the summer mean background winds, the anomalous rising motion at the center of convection advects these summer mean background winds vertically, inducing the barotropic westerly anomalies at the center of the convection. The Coriolis effect on these enhanced westerly flows generates the barotropic divergence (equivalent to the tropospheric divergence), which results in the boundary layer moisture convergence north of precipitation.

In Fig. 5, the barotropic (tropospheric) divergence tendency is represented in terms of dimensionless barotropic moisture-divergence tendency $\left[(\partial / \partial t)\left(\left(\partial v^{\prime} / \partial y\right)\right)^{+}\right.$ $\left.\left(2 \bar{q}_{e}-\bar{q}_{2}\right)\right]$. This barotropic moisture-divergence ten- 
Barotropic $\partial\left(\partial v^{\prime} / \partial y\right) / \partial t *\left(2 \bar{q}_{e}-\bar{q}_{2}\right)$ and prec. rate

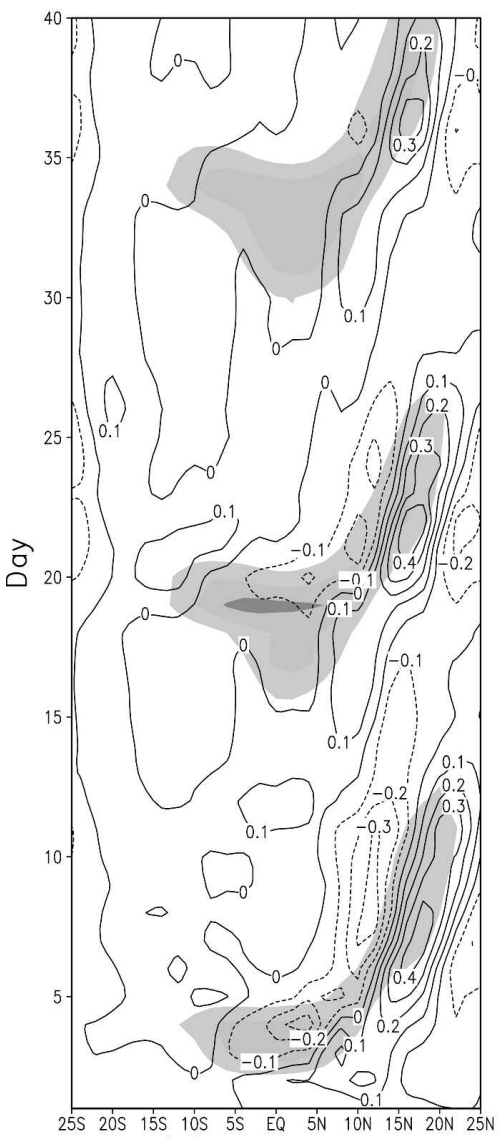

(a) Control

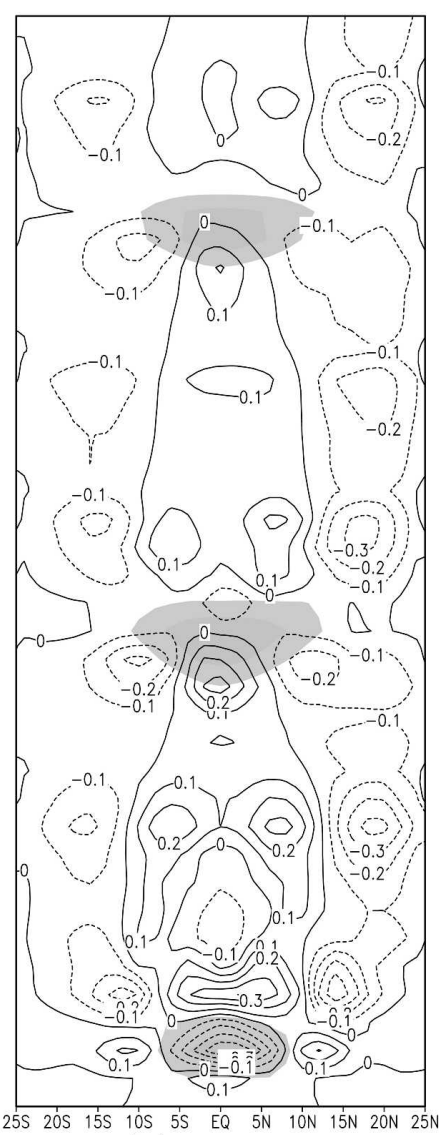

(b) Exp.1

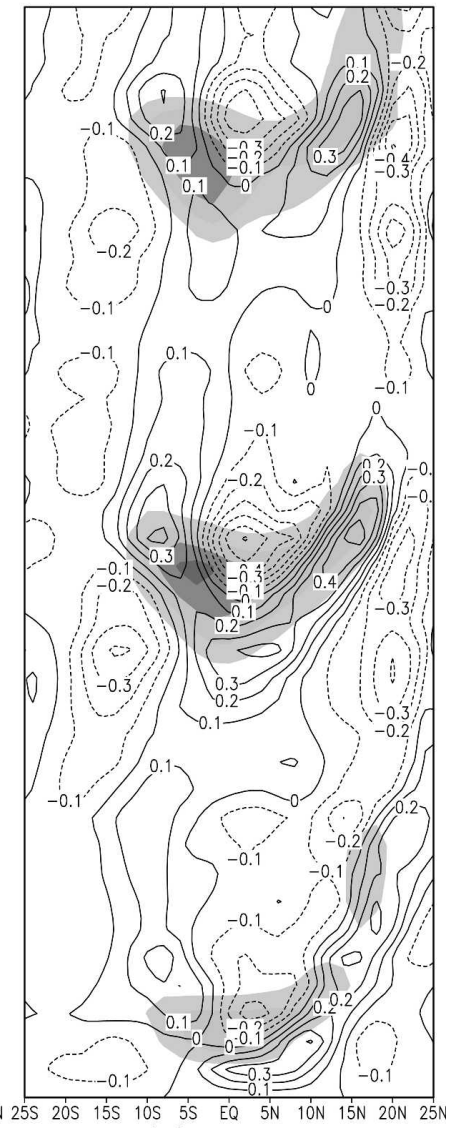

(c) $\operatorname{Exp.2}$

shade: dimensionless prec. rate

\section{contour: dimensionless barotropic $\partial\left(\partial v^{\prime} / \partial y\right) / \partial t *\left(2 \bar{q}_{0}-\bar{q}_{2}\right)$}

FIG. 5. Zonally averaged $\left(60^{\circ}-100^{\circ} \mathrm{E}\right)$, latitudinal variation of dimensionless precipitation rate (shaded) and dimensionless barotropic mode of moisture-divergence tendency $\left[(\partial / \partial t)\left(\left(\partial v^{\prime} / \partial y\right)\right)^{+}\left(2 \bar{q}_{e}-\bar{q}_{2}\right)\right]$ from day 1 to day 40 in the (a) control run, (b) expt 1, and (c) expt 2.

dency includes the effect of the summer mean moisture content, so that it can be related to the tendency of the precipitation. That is,

$$
\frac{\partial}{\partial t} \operatorname{Pr} \approx \Delta p\left[\frac{\partial}{\partial t}\left(\frac{\partial v^{\prime+}}{\partial y}\right)\left(2 \bar{q}_{e}-\bar{q}_{2}\right)\right] .
$$

Thus, the area of positive contours in the control run (Fig. 5a), experiment 1 (Fig. 5b), and experiment 2 (Fig. $5 c)$ indicates the region where the increase of the tropospheric divergence induces the boundary moisture convergence, resulting in precipitation. In the control run (Fig. 5a), the positive barotropic moisture-divergence tendency (positive contour) is located north of the precipitation (shade) from $10^{\circ}$ to $20^{\circ} \mathrm{N}$. This phase difference between barotropic divergence and convec- tion confirms that the northward-propagating mechanism of 2D model works effectively in the presence of the Kelvin-Rossby wave packet.

In the absence of summer mean winds in experiment 1 , convection at the equator does not propagate either north or south (Fig. 5b). The phase between barotropic divergence and convection is also different (Fig. 5b) from the control run. The northward-propagating component of the BSISO reoccurs in experiment 2 (Fig. 5c), as implied in the diagonally elongated structure of the convective band (Fig. 4, right panels). The similarity between the control run (Fig. 5a) and experiment 2 (Fig. 5c) in the phase relationship between barotropic divergence and convection further suggests that there is a consistent barotropic structure, which is connected to 
the northward propagation of BSISO. The favorable condition for this structure seems to be imbedded in meridional and vertical structures of summer mean zonal winds over the Indian Ocean region.

\section{Summary}

This work is an extension of the two-dimensional model study by Drbohlav and Wang (2005). Using a two-dimensional intermediate atmospheric model (2D model), they examined the mechanism of the northward-propagating boreal summer intraseasonal oscillation (BSISO). Since the 2D model is zonally symmetric, the zonally propagating Kelvin-Rossby wave packet is excluded in the previous study. Thus, the mechanism found in the 2D model was independent of the KelvinRossby wave packet (wave-independent mechanism hereafter). In this study, the three-dimensional intermediate atmospheric model (3D model) is used in simulating the northward-propagating BSISO, and the relevance of the wave-independent mechanism is reexamined in the 3D model.

One way of examining is to see if the essential components of the wave-independent barotropic mechanism still exist in the BSISO of the 3D model. The essential component is the phase relationship between the convection and the barotropic divergence tendency. Since the barotropic divergence tendency triggers the convergence in the boundary layer, the northward-positioned barotropic divergence tendency with respect to the existing convection is essential for the northward propagation of the convection. Since the easterly vertical shear in the summer mean flow is suggested to be the cause of this phase relationship between the barotropic divergence and convection in the 2D model, two experiments are conducted in order to examine whether the phase relationship between the barotropic divergence and convection still resides in the Kelvin-Rossby wave packet; and if so, the cause of this phase relationship is indeed the easterly vertical shear in the summer mean winds.

In the first experiment, all the basic-state winds are excluded. As a response, the phase relationship between the barotropic divergence and convection disappears, and the Kelvin-Rossby wave-type convection produces the zonally elongated band of convection rather than the northwestward-tilted one. When the meridional and vertical variations of summer mean zonal winds are included in the second experiment, horizontal and vertical structures of northward-propagating BSISO reoccurs. These results imply that the uniqueness in the horizontal and vertical structures of the Kelvin-Rossby wave packet in the Asian summer monsoon region comes from the meridional and vertical structures of summer mean zonal winds, especially over the Indian Ocean region. Without these structures in the basic-state zonal winds over the Indian Ocean region, the Kelvin-Rossby wave packet does not produce the northward propagation of convection. This implies that the northward-propagating BSISO can be understood as an independent feature of the Indian Ocean region.

Acknowledgments. The authors acknowledge the support from the NSF Climate Dynamics Program Award (ATM03-29531).

\section{REFERENCES}

Anderson, J. R., and D. E. Stevens, 1987: The presence of linear wavelike modes in a zonally symmetric model of the tropical atmosphere. J. Atmos. Sci., 44, 2115-2127.

Drbohlav, H.-K. L., 2002: The mechanism of intraseasonal oscillation in the south Asian monsoon region. Ph.D. dissertation, University of Hawaii at Manoa, $240 \mathrm{pp}$.

- , and B. Wang, 2005: Mechanism of the northward-propagating intraseasonal oscillation: Insights from a zonally symmetric model. J. Climate, 18, 952-972.

$\mathrm{Fu}, \mathrm{X}$., and B. Wang, 1999: The role of longwave radiation and boundary layer thermodynamics in forcing tropical surface winds. J. Climate, 12, 1049-1069.

,,-- T. Li, and J. P. McCreary, 2003: Coupling between northward-propagating intraseasonal oscillations and sea surface temperature in the Indian Ocean. J. Atmos. Sci., 60, 1733-1753.

Goswami, B. N., and J. Shukla, 1984: Quasi-periodic oscillations in a symmetrical general circulation model. J. Atmos. Sci., 41, $20-37$.

Hsu, H.-H., C.-H. Weng, and C.-H. Wu, 2004: Contrasting characteristics between the Northward and Eastward Propagation of the intraseasonal oscillation during the boreal summer. $J$. Climate, 17, 727-743.

Jiang, X., T. Li, and B. Wang, 2004: Structures and mechanisms of the northward propagating boreal summer intraseasonal oscillation. J. Climate, 17, 1022-1039.

Kemball-Cook, S., and B. Wang, 2001: Equatorial waves and airsea interaction in the boreal summer intraseasonal oscillation. J. Climate, 14, 2923-2942.

Krishnamurti, T. N., and D. Subrahmanyam, 1982: The 30-50 day mode at $850 \mathrm{mb}$ during MONEX. J. Atmos. Sci., 39, 2088-2095.

Lau, K. M., and P. H. Chan, 1986: The 40-50 day oscillation and the El Niño/Southern Oscillation: A new perspective. Bull. Amer. Meteor. Soc., 67, 533-534.

Lawrence, D. M., and P. J. Webster, 2002: The boreal summer intraseasonal oscillation: Relationship between northward and eastward movement of convection. J. Atmos. Sci., 59, 1593-1606.

Wang, B., 2005: Theories. Intraseasonal Variability in the Atmosphere-Ocean Climate System, W. K.-M. Lau and D. E. Waliser, Eds., Springer-Verlag, 307-362.

_, and X. Xie, 1997: A model for boreal summer intraseasonal oscillation. J. Atmos. Sci., 54, 72-86.

Webster, P. J., 1983: Mechanisms of monsoon low-frequency variability: Surface hydrological effects. J. Atmos. Sci., 40, 2110-2124.

Yasunari, T., 1979: Cloudiness fluctuations associated with Northern Hemisphere summer monsoon. J. Meteor. Soc. Japan, 57, 227-242. 